\title{
Mini Open Foraminotomy (MOF) for Cervical Radiculopathy: Technical Note
}

\author{
Jun Takahashi", Kaoru Aoki, Nobuhide Ogihara, Hiroki Hirabayashi, Hiroyuki Hashidate and \\ Hiroyuki Kato
}

Department of Orthopaedic Surgery, Shinshu University, School of Medicine, 3-1-1 Asahi, Matsumoto-City, Nagano, 390-8621, Japan

\begin{abstract}
Background: Favorable surgical results had been reported in cervical posterior foraminotomy using endoscopy; however, the learning curve for the surgeon is steep. We therefore developed a procedure that can be performed more easily and with small incision, called "Mini Open Foraminotomy (MOF)", using a tubular retractor (22mm diameter) under direct vision. The purpose of this study was to demonstrate the surgical procedure about MOF for cervical radiculopathy and assess a postoperative result of MOF.

Materials/Methods: We performed MOF on 19 consecutive patients (15 males and 4 females) with cervical radiculopathy. Average age at time of operation was 48.9 years. Average follow-up period was 30.6 months. Spondylotic radiculopathy was diagnosed in 12 cases and disc herniation in seven cases. Skin incision was approximately $3 \mathrm{~cm}$. Large (22mm diameter) METRx tube with illumination was fixed into paravertebral muscle. The lower articular process of the upper vertebra and the upper articular process of the lower vertebra were shaved with pneumatic drill and Kerrison rongeur to decompress the nerve root under direct vision.

Results: Mean operation time was $78 \pm 26$ minutes. Mean hemorrhage weight was $50 \pm 46 \mathrm{ml}$. All patients were able to stand and walk without neck collars on the first postoperative day, with dramatic reduction of radicular pain. Mean VAS of radicular pain showed significant improvement at final follow up compared with that before surgery $(0.5 \pm 1.1$ and $7.1 \pm 2.6$, respectively; $\mathrm{p}<0.0001)$.

Conclusions: Mini open foraminotomy is a less invasive, more easily, and safe procedure, moreover effective surgical option for the management of cervical radiculopathy.
\end{abstract}

Keywords: Foraminotomy, cervical radiculopathy, less invasion.

\section{INTRODUCTION}

Various anterior and posterior operative approaches for the treatment of cervical radiculopathy have been reported [1-5]. Frykholm [6] and Scoville [7] described posterior foraminotomy through partial resection of the medial part of facet joint to relieve the compression of the cervical nerve root in radiculopathy patients. Conventional posterior approaches have the disadvantage of the detaching the extensor cervical muscles from the laminae and the spinous process $[8,9]$. This operative trauma to the cervical paraspinal muscles is a major cause of postoperative complications that may be in the form of persistent neck and shoulder pain, and sometimes spinal instability may be the end result [10-12].

In contrast, favorable surgical results had been reported in cervical posterior foraminotomy using endoscopy by Adamson [13] and Fessler et al. [14] or using operating microscope by Boehm et al. [15]. This procedure, which employs blunt retraction of paravertebral muscle through a small incision, can be performed with less postoperative adverse reactions such as neck pain and shoulder stiffness: however, the

*Address correspondence to this author at the Department of Orthopaedic Surgery, Shinshu University, School of Medicine, 3-1-1 Asahi, Matsumotocity, Nagano, 390-8621, Japan; Tel: 81-263-37-2659; Fax: 81-263-35-8844; E-mail: jtaka@shinshu-u.ac.jp learning curve for the surgeon is steep. We therefore developed a procedure that can be performed more easily and with small incision, called "mini open foraminotomy (MOF)", consisting of blunt retraction of paravertebral muscle and insertion of a tubular retractor $(22 \mathrm{~mm})$ under direct vision. The purpose of this study was to demonstrate the surgical procedure about MOF for cervical radiculopathy and assess a postoperative result of MOF.

\section{MATERIALS AND METHODS}

Nineteen (15 men and 4 women) consecutive patients were treated with MOF for cervical radiculopathy between May 2003 and June 2007. Patients ranged from 30 to 65 years of age, with a mean age of $48.9 \pm 8.8($ mean \pm SD) years. All patients underwent diagnostic imaging of the cervical spine via a combination of plain static/dynamic x-ray, MRI, CT, myelography, CTM, and selective nerve root blocks. Eight of the cases were performed on the right side and 11 on the left. Operated diseases comprised 12 cases of spondylotic foraminal stenosis and seven cases of disc herniation. Spinal levels included C3/4 ( $\mathrm{n}=1), \mathrm{C} 4 / 5(\mathrm{n}=2), \mathrm{C} / 6(\mathrm{n}=6)$, C6/7 $(n=9)$, and C7/T1 $(n=1)$. Surgery was indicated for cases that satisfied two conditions: confirmation of foraminal stenosis by imaging and observation of corresponding neurological findings; and temporary relief from radicular pain that had remained refractory after 3 months of conservative 
therapy. The evaluated parameters were: surgical time; blood loss; Creatine phosphokinase(CPK) and C-reactive protein (CRP) values before surgery and 1 day after surgery; number of days with fever $\left(\geq 37^{\circ} \mathrm{C}\right)$ after surgery; Modified version of the Oswestry Index, called NDI [16], Visual Analog Scale (VAS) of neck pain, of radicular pain before surgery, and at the final follow up. Furthermore, percent of facetectomy was measured using postoperative computer tomography.

Statistical analysis was performed with Student t-test using Stat View (SAS Institute, Cary, NC) as software. Mean and SD were calculated and statistical significance was set at a p-value less than 0.05 .

\section{Surgical Technique}

After the induction of general endotracheal anesthesia, the patients were positioned prone on a four-poster frame. The neck was mildly flexed and head fixated in a three-point Mayfield headrest. A fluoroscopic C-arm was then brought into the surgical field so that real-time lateral fluoroscopic images could be obtained. Following confirmation of spinal level by fluoroscopic C-arm lateralview, a 3-cm skin incision was made about $1.5 \mathrm{~cm}$ lateral to the center (Fig. 1). The fascia was then incised by electrocautery, paravertebral muscle was retracted with dilater, finger and/or cobb elevator, and a METRx large tube (22 $\mathrm{mm}$ diameter, Medtronic Sofamor Danek; Memphis, TN) was inserted. Real-time lateral radiographic images were obtained as often as needed to ensure a proper working trajectory throughout this process (Fig. 2). The working channel (tubular retractor) was then attached to a flexible retractor affixed to the operating table side rail and locked in position at the junction of the lamina and lateral mass. A METRx Radiance Illumination Guide (Medtronic Sofamor Danek; Memphis, TN) was then attached to the tubular retractor, and surgery was performed under direct vision (Fig. 3). Standard spinal surgery devices are employed, as the height of the tubular retractor was low.

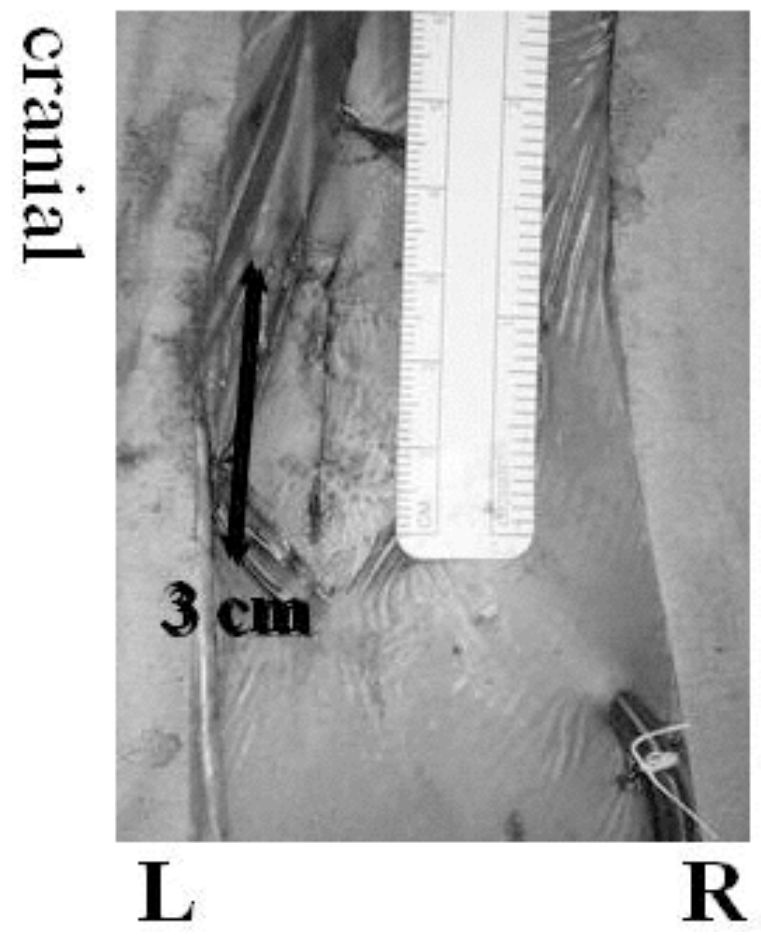

Fig. (1). Skin incision was about $3 \mathrm{~cm}$.

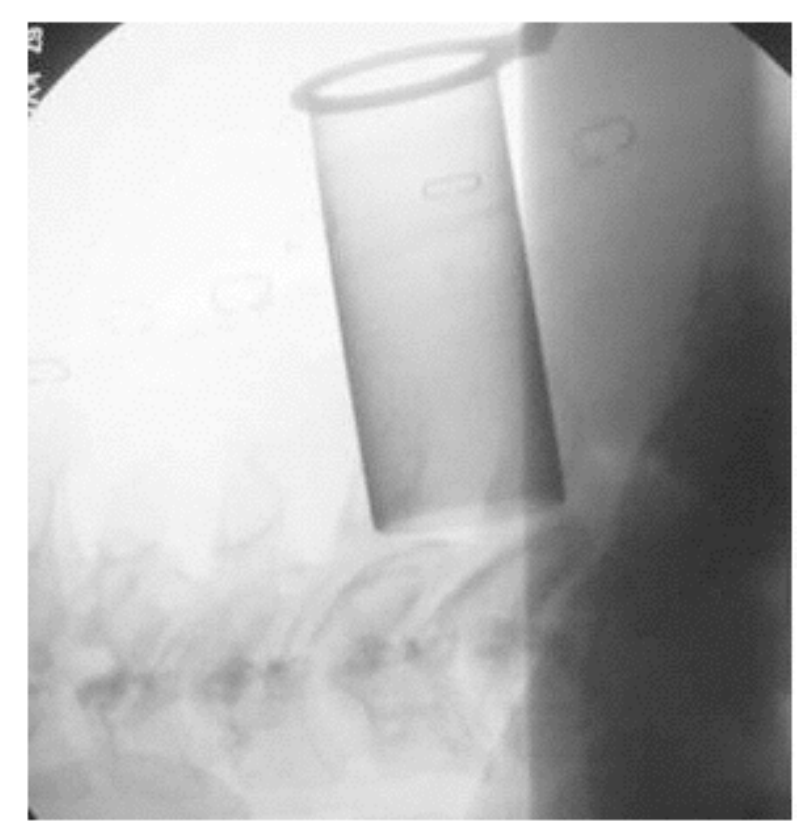

Fig. (2). A large METRx tube was inserted to culprit intervertebral space. Spinal level was confirmed by fluoroscopic C-arm lateral view.
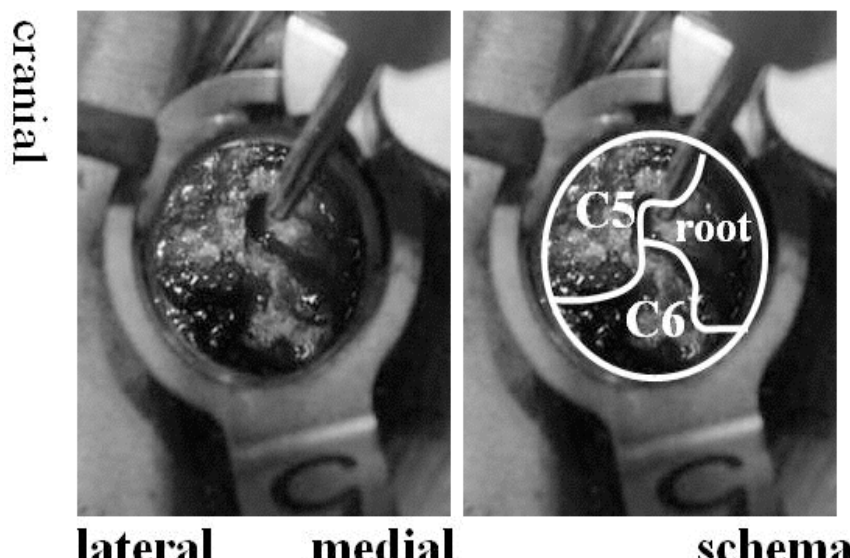

schema

Fig. (3). Image after completion of nerve root decompression and its schema.

The procedure is designed to deroof the neural foramen, with no attempt being made to remove any anterior osteophytes or hard disc. Lower margin and inferior facet of upper lamina and superior facet of lower cervical vertebrae were removed with a high-speed drill and Kerrison punch ( 1 or 2 $\mathrm{mm}$ ) to perform decompression of nerve root under direct vision. Approximately $2 / 5$ to $1 / 2$ of the medial facet joint was removed, leaving at least $50 \%$ in place, not to create instability by removing the facets [12]. Generally, circular bone removal (approximately $1 \mathrm{~cm}$ diameter) was conducted (Fig. 4). Sufficient root decompression was carefully proved by a small nerve hook, with which the sufficiency of decompression could be checked in the entire foramen. Bleeding from this epidural vein could generally be controlled by bipolar coagulation or by gentle pressure on cottonoid. Suction drain was then placed and skin was fixed with Steri-Strip ${ }^{T M}$. No neck collar was used after surgery, and patients were allowed to walk from the day after surgery. Surgical wound is small and less visible (Fig. 5). 


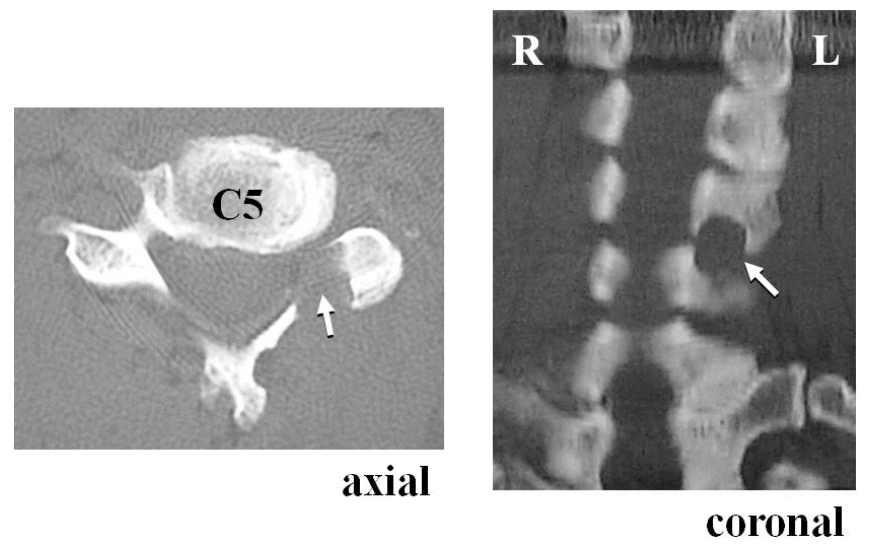

Fig. (4). Postoperative CT revealed sufficient decompression of the foramen.

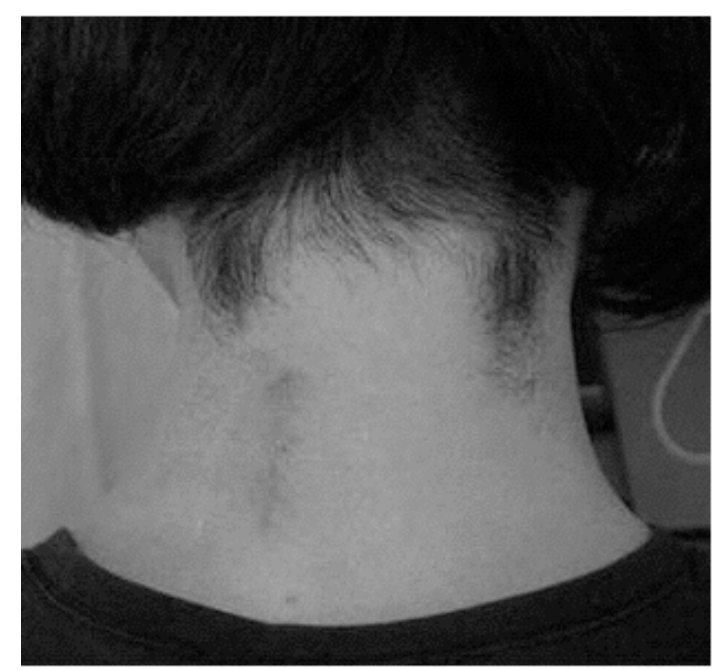

Fig. (5). Surgical wound is small and less visible.

\section{RESULTS}

Evaluation parameters were as follows: Mean surgical time, $78.2 \pm 26.1 \mathrm{~min}$. (range: $46 \sim 144 \mathrm{~min}$.); mean blood loss, 49.7 $\pm 45.5 \mathrm{~g}(10 \sim 120 \mathrm{~g})$; mean CPK and CRP values before surgery, $99.2 \pm 35.7 \mathrm{mg} / \mathrm{dl}(69 \sim 165 \mathrm{mg} / \mathrm{dl})$ and $0.05 \pm 0.10 \mathrm{mg} / \mathrm{dl}$ (0 0.34mg/dl), mean CPK and CRP values at 1 day after surgery, $274.1 \pm 157.8 \mathrm{mg} / \mathrm{dl}(87 \sim 682 \mathrm{mg} / \mathrm{dl})$ and $0.41 \pm 0.46 \mathrm{mg} / \mathrm{dl}$ $(0.05 \sim 1.98 \mathrm{mg} / \mathrm{dl})$, respectively; and number of days with fever $\left(\geq 37^{\circ} \mathrm{C}\right), 1.5 \pm 1.3$ days $(0 \sim 4$ days $)$.

With mean postoperative follow up of $30.6 \pm 13.7$ (12 60) months, mean NDI showed significant improvement at the final follow up compared with that before surgery (8.9 \pm 7.6 [0 23] and 26.9 \pm 10.2 [9 44], respectively; $p<0.0001)$. Mean VAS of neck pain showed significant improvement at the final follow up compared with that before surgery $(1.6 \pm 1.8$ [0 5] and 5.7 $\pm 3.2[0 \sim 10]$, respectively; $p<0.0001)$, and VAS of radicular pain of the same period also showed significant improvement $(0.5 \pm 1.1[0 \sim 4]$ and $7.1 \pm 2.6$ [0 10], respectively; $\mathrm{p}<0.0001)$. In any cases, radicular pain had dramatically improved immediately after surgery. Mean percent of facetectomy was $45.5 \pm 2.5$ [40-50] \% using postoperative computer tomography. There were no general postoperative complications, no dural punctures and no wound infections. Post operative neurological deterioration did not occur in any cases.

\section{DISCUSSION}

Our results showed that MOF was a less invasive, easier and safe procedure, moreover effective surgical option for the management of cervical radiculopathy. Parameters related to surgical invasion in our procedure were mean surgical time of $78.2 \mathrm{~min}$ and blood loss of $49.7 \mathrm{~g}$, showing marked reduction in surgical time and blood loss compared to open foraminotomy reported by Fessler et al. [14] in which these parameters were $171 \mathrm{~min}$. and $246 \mathrm{~g}$, respectively. On the other hand, the mean surgical time of endoscopic foraminotomy was reported 28-184 minutes and the mean blood loss volume of that was reported no measurable blood loss to $138 \mathrm{ml}[14,17,18]$. I think that the surgical invasion of $\mathrm{MOF}$ is almost equal compare to endoscopic foraminotomy.

Williams reported that operative time could be estimated as one hour for a single level foraminotomy and blood loss rarely exceeded 100cc [19]. Although we could not find the data; e.g. CRP and CPK, it is reasonable to suppose that MOF without muscle dissection may be a less invasive than conventional microscopic foraminotomy. Besides, according to a report by Takahashi et al. [20], mean CRP value 1 day after spinal surgery which only decompression without instrumentation was conducted was $1.21 \pm 1.26 \mathrm{mg} / \mathrm{dl}$ (mean \pm SD) (range: 0 3.26), while that of MOF was $0.41 \pm 0.46$ $\mathrm{mg} / \mathrm{dl}(0.05 \sim 1.98)$, showing significant reduction $(\mathrm{p}<0.05)$ by MOF surgery. Furthermore, the number of days with fever $\left(\geq 37^{\circ} \mathrm{C}\right)$ was $3.6 \pm 2.3(0 \sim 11$ days $)$ and $1.5 \pm 1.3$ days $(0 \sim 4$ days), respectively $(\mathrm{p}<0.01)$. These findings suggest that MOF is less invasion foraminotomy.

General indication of posterior foraminotomy is a radiculopathy that is refractory to conservative therapy, with dominant posterior compression confirmed by selective nerve root blocks. MOF was also performed in seven cases of cervical disc herniation, however, and these subjects were treated by foraminotomy without herniotomy, showing good surgical results. In these surgeries, spontaneous reduction of hernia was observed by postoperative MRI, consistent with a report by Maigne et al. [21] that indicated spontaneous reduction of cervical disc herniation as well as lumbar disc herniation. Posterior herniotomy was additionally performed after foraminotomy in reports of Adamson [13] and Fessler et al. [14], but this might be unnecessary considering the risks of epidural plexus bleeding or nerve root damage.

Zdeblick et al. performed successive 25\%, 50\%, 75\%, and $100 \%$ facetectomy in an vitro model to evaluate the impact of progressive facet resection on instability; significant segmental hypermobility occurred with greater than $50 \%$ facer resection [12]. In all our cases, maximum $\%$ of facetectomy was $50 \%$ (mean: $45.5 \pm 2.5 \%$ ). Spinal instability was not encountered in our patients.

To our knowledge, this is the first report of posterior foraminotomy using tubular retractor under direct vision. Advantages of MOF include small incision, less invasion, potentially less postoperative axial pain compared to anterior decompression and fusion or conventional open or microscopic posterior foraminotomy, absence of necessity of external support, and little possibility of adjacent-level disorder. Mean VAS of neck pain showed significant improvement at the final follow up compared with that before sur- 
gery. Consequently, this technique that minimizes trauma to the posterior paraspinal muscles of the neck offers many advantages and a better functional outcome. Additionally, this procedure requires less experience compared to endoscopic surgery, because it is performed under direct vision. Although it is difficult to perform operation using the common tubular retractor $(16 \mathrm{~mm}$ or $18 \mathrm{~mm}$ diameter), I strongly believe that this technique is easier using this $22 \mathrm{~mm}$ tubular retractor under direct vision.

In summary, mini open foraminotomy is easier and safe procedure compared with microscopic and endoscopic foraminotomy. Moreover, this technique is a less invasive and effective surgical option for the management of nerve root compression secondary to posterolateral disc herniation or foraminal spondylotic stenosis.

\section{REFERENCES}

[1] Cloward RB. The anterior approach for removal of raptured cervical disks. J Neurosurg 1958; 15: 602-17.

[2] Bailey R, Badgley C. Stabilization of cervical spine by anterior fusion. J Bone Joint Surg 1960; 42A: 565-94.

[3] Aronson N. The management of soft cervical disc protrusions using the Smith-Robinson approach. Clin Neurosurg 1973; 20: 253-8

[4] Aldrich F. Posterolateral microdiscectomy for cervical monoradiculopathy caused by posterolateral soft cervical disc sequestration. J Neurosurg 1990; 72: 370-7.

[5] Fager CA. Posterolateral approach to ruptured median and paramedian cervical disc. Surg Neurol 1983; 20: 443-52.

[6] Frykholm R. Cervical nerve root compression resulting from disc degeneration and root sleeve fibrosis. Acta Chir Scand 1951; 160: 1-149.

[7] Scoville WB. Cervical spondylosis treated by bilateral facetectomy and laminectomy. J Neurosurg 1961; 18: 423-8.

[8] Cusick JF, Larson SJ. Foraminomy. In: Shrk HH, Ed. The cervical spine: An atlas of surgical procedures. LB Lippincott, Philadelphia 1994; pp. 213-8.
[9] Hoski JJ, Eismont FJ. Posterior positioning and approaches. In: Sherk HH, Ed. The cervical spine: an atlas of surgical procedures. LB Lippincott, Philadelphia, 1994; pp. 17-35.

[10] Hosono N, Yonenobu K, Ono K. Neck and shoulder pain afterlaminoplasty: a noticeable complication. Spine 1996; 21: 1969-73.

[11] Kawaguchi Y, Matsui H, Ishihara H, Gejo R, Yoshino O. Axial symptoms after en bloc cervical laminoplasty. J Spinal Disord 1999; 12: 392-5.

[12] Zdeblick TA, Zou D, Warden KE, et al. Cervical stability after foraminotomy: a biomechanical in vitro analysis. J Bone Joint Surg 1992; 74A: 22-7.

[13] Adamson TE. Microendoscopic posterior cervical laminoforaminotomy for unilateral radiculopathy : results of a new technique in 100 cases. J Neurosurg (spine) 2001; 95: 51-7.

[14] Fessler RG, Khoo LT. Minimally invasive cervical microendoscopic foraminotomy: an initial clinical experience. Neurosurgery 2002; 51: 37-45.

[15] Boehm H, Greiner-Perth R, El-Saghir, Allam Y. A New minimally invasive posterior approach for the treatment of cervical radiculopathy: surgical technique and preliminary results. Eur Spine J 2003; 12: 268-73.

[16] Vernon H, Mior S. The neck disability index : a study of reliability and validity. J Manipulative Physiol Ther 1991; 14: 409-15.

[17] Ruetten S, Komp M, Merk H, Godolias G. Full-endoscopic cercical posterior foraminotomy for the operation of lateral disc heniations using 5.9mm endoscopes. Spine 2008; 33: 940-8.

[18] Burke TG, Caputy A. Microendoscopic cervical foraminotomy: a cadaveric model and clinical application for cervical radiculopathy. Neurosurg Focus 1999; 7(5): Article 4.

[19] Williams RW. Microcervical foraminotomy. A surgical alternative for intractable radicular pain. Spine 1983; 8: 708-16.

[20] Takahashi J, Ebara S, Kamimura M, et al. Early-phase enhanced inflammatory reaction after spinal instrumentation surgery. Spine 2001; 26: 1698-704.

[21] Maigne JY, Deligne L. Computer tomographic follow-up study of 21 cases of nonoperatively treated cervical intervertebral soft disc herniation. Spine 1994; 19: 189-91. 